\title{
Michel Foucault, a gestão dos ilegalismos e a razão criminológica neoliberal
}

Michel Foucault, the management of illegalisms and the

\author{
neoliberal criminological reason
}

Diego dos SANTOS REIS ${ }^{\mathrm{a}}$

\section{Resumo}

O presente artigo busca analisar de que modo os problemas da segurança e da economia das punições passam a ser centrais no cálculo político-econômico da racionalidade neoliberal. Como propõe Michel Foucault em seu curso Nascimento da Biopolítica, de 1979, a tecnologia de governo neoliberal conceberia o aparato estatal como "efeito móvel de um regime de governamentalidades múltiplas". É o enfoque econômico, portanto, que permitirá pôr à prova a eficácia da ação governamental, a partir da avaliação do custo-benefício das intervenções na esfera do mercado e da sociedade, conforme a proposição dos teóricos neoliberais. Essa crítica mercantil direciona-se ao que é concebido como "dispêndio" das ações econômicas do poder público, dado que o mercado se torna "uma espécie de tribunal econômico permanente em face do governo", como sugere Foucault. Nesse cenário, no qual se ampliam as demandas punitivas, a eficiência de atuação do sistema de justiça criminal dos Estados será medida pela avaliação do mercado e da economia, tendo em vista os seus efeitos. Tratar-se-á, então, de refletir sobre o funcionamento do poder punitivo em moldes econômicos, isto é, pela via da problematização dos custos da delinquência e dos modos de torná-los o menos dispendioso possível e com a máxima eficiência.

Palavras-chave: Gestão dos ilegalismos. Governamentalidade neoliberal. Segurança. Subjetividade. Michel Foucault.

\footnotetext{
a Universidade Federal do Rio de Janeiro (UFRJ), Rio de Janeiro, RJ, Brasil. Doutor em Filosofia, e-mail: diegoreis.br@gmail.com
} 


\begin{abstract}
This article analyzes how the problems of security and economy of punishment are central to the political and economic calculation of neoliberal rationality. As Michel Foucault proposes in his course of 1979, Birth of Biopolitics, neoliberal government technology would conceive the state apparatus as "the mobile effect of a regime of multiple governmentalities". It is the economic approach, therefore, that will allow to test the effectiveness of governmental action, from the evaluation of the cost-benefit of interventions in the sphere of the market and society, according to the proposition of neoliberal theorists. This mercantile critique is directed to what is conceived as "expenditure" of the economic actions of the public power, since the market becomes "a sort of permanent economic tribunal confronting government", as Foucault suggests. In this scenario, in which the punitive demands are amplified, the efficiency of the criminal justice system of the states will be measured by the market and economic evaluation, with the objective of their effects. It will then be a question of reflecting on the functioning of punitive power in an economic way, that is to say, by means of problematizing the costs of delinquency and ways of making them the least expensive possible and with maximum efficiency.
\end{abstract}

Keywords: Management of illegalisms. Neoliberal governmentality. Security. Subjectivity. Michel Foucault.

No curso Nascimento da Biopolitica, de 1979, Foucault analisa as afinidades biopolíticas das artes de governo liberais e neoliberais. Tratava-se, naquele momento, de pensar o desafio específico do neoliberalismo enquanto racionalidade governamental e de que modo o exercício do poder político seria regulado com base nos princípios de uma economia concorrencial de mercado.

Se, ao final da década de 1970, a questão ainda não suscitava consideráveis dissensões à sua recepção, devido à paulatina escalada dos governos de inspiração neoliberal, quando o curso do filósofo foi publicado em livro, em 2004, refigurou-se toda uma dimensão despercebida destas análises. Como lembra Aeschimann (2013), em ensaio publicado no Le Nouvel Observateur, o título Nascimento da Biopolítica não facilitou a difusão dessas análises nos meios de discussão da economia política, devendo-se esperar até 2009, à ocasião da publicação de $A$ Nova Razão do Mundo, de Pierre Dardot e Christian Laval, para que emergisse uma leitura capaz de ativar o potencial crítico da interpretação foucaultiana. 
O que o trabalho de Dardot e Laval (2009) explicitaria seriam as condições históricas de emergência da governamentalidade neoliberal e como ela operaria um redimensionamento prático e discursivo do exercício político, ao estender o crivo econômico a todas as esferas da vida. Já em Segurança, Território, População (FOUCAULT, 2004), ao tratar das questões centrais que seriam debatidas ao longo do curso, nos marcos da razão de Estado, da governamentalidade e da biopolítica, se antevê a abordagem crítica de Foucault aos efeitos de verdade, à subjetivação na esfera política e aos modos de vida suscitados por essas estratégias de governo.

Atravessada pela ideia de que "governa-se sempre demais", a governamentalidade de Estado no pensamento e na prática neoliberais não deixou de ser questionada em toda sua extensão. Convertidas em premissas dominantes da experiência política no mundo ocidental, sob a chancela do modelo hegemônico norte-americano, a compressão do Estado em detrimento dos mercados desregulamentados — sobretudo, o financeiro - e a centralidade das relações pautadas pelos operadores econômicos constituem, ainda hoje, injunções de ajustamento que parecem atribuir aos mercados a função simultânea de paradigmas e de crítica permanente da ação governamental no interior dos processos político-econômicos a que se encontram vinculados.

O modelo do capital neoliberal, como forma de gestão das massas e da máquina pública, apoia-se em um pacto entre governo e segurança, que funciona normativamente como quadro de referência para todos os aspectos da vida. Não é de admirar que o neoliberalismo se apresente como a razão do capitalismo contemporâneo, tal como afirmam Dardot e Laval (2009), plenamente assumido como construção histórica e como norma geral da vida.

Caracterizado, de modo geral, pela verve crítica em relação a medidas políticas e teorias de inspiração social, como marxismos, comunismos e keynesianismo, o neoliberalismo vinculou-se historicamente a tradições de pensadores conservadores, que sustentam o discurso ideológico-político de um projeto de privatização do social, de redução das políticas assistenciais e de contração do Estado. 
Foucault (2008, p. 437) afirma que "o liberalismo se apresentou, num contexto bem definido, como uma crítica da irracionalidade própria do excesso de governo e como um retorno a uma tecnologia de governo frugal". O liberalismo, nessa via, constitui-se como um "esquema regulador da prática governamental" (FOUCAULT, 2008, p. 434) e, sobretudo, como um tipo de racionalidade que é indissociável dos procedimentos por meio dos quais a conduta dos indivíduos é direcionada a determinados fins.

A atualidade dessas discussões, porém, não remete apenas à emergência de uma razão de governo que foi capaz de alterar profundamente os cálculos políticos e a gestão das populações em escala mundial. Desde o raiar do século XXI, estão em vias de se agravar os mecanismos e os procedimentos forjados no bojo das políticas neoliberais, entendidas não como uma ideologia ou uma doutrina econômica, mas como um projeto de sociedade, que visa a instituir os mercados como centros referenciais e a concorrência como princípio de verdade das práticas, dos discursos e das condutas. É o advento da empresa e do empreendedorismo de si, tal como sugeririam Foucault (2008) e Deleuze (2013), como figuras referenciais na formação cidadã e do capital humano de maior valor. Não à toa, o molde do sujeito neoliberal será o do indivíduo empreendedor, na medida em que ele:

É o indivíduo eficiente e competitivo que busca a maximizar seu capital humano em todos os domínios, que não busca somente a se projetar no futuro e a calcular seus ganhos e seus custos como o velho homem econômico, mas que procura, sobretudo, trabalhar sobre simesmo a fim de se transformar permanentemente, de melhorar, de se tornar sempre mais eficiente (DARDOT; LAVAL, 2009, p. 414).

No nexo entre ação dos efeitos políticos e a cadeia de responsabilidade individual, há um alinhamento entre as "escolhas singulares dos cidadãos com os objetivos do governo", pois “a sua liberdade e a sua subjetividade podem de tal modo se tornar aliadas, e não desconfiadas", que se traduzem em "uma boa ordem que governa tanto a política quanto a sociedade” (ROSE; MILLER, 1992, p. 188189). Com o advento dessa arte de governo neoliberal, em nome da máxima eficiência administrativa, o saber da economia política e o limite das práticas governamentais serão os marcos privilegiados. 
Tratou-se, então, da emergência de uma racionalidade política ancorada no conhecimento de um suposto "naturalismo" dos fenômenos econômicos, com a ampliação da racionalidade de mercado e a aplicação da grade econômica ao conjunto de relações sociais, políticas, trabalhistas e afetivas. Nada escapa às redes do pensamento econômico, nem mesmo o conjunto das relações sociais ou os fatos comportamentais individuais, que passam a ser decifrados sob o prisma da economia de mercado.

\section{Tolerância zero?}

É o enfoque econômico que permitirá pôr à prova a eficácia da ação governamental, conforme sustentam os teóricos neoliberais, a partir da avaliação do custo-benefício das intervenções na esfera do mercado e da sociedade. Essa crítica mercantil direciona-se ao que se concebe como "dispêndio" das ações econômicas do poder público, dado que o mercado se torna "uma espécie de tribunal econômico permanente em face do governo" (FOUCAULT, 2008, p. 339). Tribunal impiedoso e burocrático, pronto para fabricar delinquentes quando for necessário, “[...] carregados de todos os vícios e responsáveis pelos maiores perigos" (FOUCAULT, 1979, p. 133).

Afinal, será preciso justificar os investimentos no sistema e na aplicação penal excludente, nesse contexto de tamanha "liberdade" e de cortes nas políticas sociais. Além, é bem verdade, da produção permanente de medos tangíveis, afeto que impossibilita que se constitua um mundo comum e justifica a guerra contra as massas miseráveis: as únicas responsáveis pelo seu fracasso. É aí que, como afirma Wacquant (2003, p. 12), “[...] o encarceramento reelabora sua missão histórica dirigindo-a à 'regulação da miséria (talvez sua perpetuação') e ao armaz̧enamento dos refugos do mercado". Demandas punitivas em resposta aos conflitos sociais, normalização da ação violenta do sistema de segurança pública, "acumulação social da violência" (MISSE, 2008) distribuída de forma desigual. Como gerir a massa periférica, produzida como resíduo imprescindível de uma ordem social pautada pelo 
individualismo democrático, pela flexibilização dos direitos sociais e pela aposta no jogo de risco do empreendedorismo de si?

\section{Crime e castigo}

Nesse cenário, no qual se ampliam as demandas punitivas, a eficiência de atuação do sistema de justiça criminal dos Estados será medida pela avaliação do mercado e da economia, tendo em vista os seus efeitos. É isso que norteará as análises neoliberais acerca da justiça penal e da criminalidade, principalmente as de Ehrlich, Stigler e Becker, que Foucault analisa na aula de 21 de março de 1979 de Nascimento da Biopolítica.

Aludindo aos reformadores do direito penal do século XVIII, Cesare Beccaria e Jeremy Bentham, os teóricos neoliberais elaboram sua reflexão sobre o funcionamento do poder punitivo em moldes econômicos, isto é, pela via da problematização dos custos da delinquência e dos modos de torná-los o menos dispendioso possível e com a máxima eficiência. O recurso mobilizado pelos reformistas é uma saída legalista. A boa lei, tal como concebida por eles, estabeleceria um princípio universal de funcionamento de modo mais econômico, com vistas à punição eficaz dos crimes prescritos por ela. Dado que o crime é uma falta contra uma regra jurídica instituída, se não há lei também não há crime. Por isso, seria imperativa a definição das penas e das punições pelas leis, de acordo com modulações que refletissem o nível de "gravidade" dos delitos.

Quanto aos tribunais penais, caberia a eles aplicar a lei previamente estabelecida aos crimes, de modo “objetivo". A consequência desses princípios é que se trama, com extrema concisão, toda uma rede de política penal, cuja mecânica funciona, sob a ótica neoliberal, baseada em princípios econômicos. Política penal e economia se encontram, finalmente, na forma dos mecanismos legais: "O homo penalis, o homem penalizável, o homem que se expõe à lei e pode ser punido pela lei, esse homo penalis é, no sentido estrito, um homo oeconomicus" (FOUCAULT, 2008, p. 341). 
Um paradoxo atravessaria, porém, a economia penal. Pois se, de um lado, a lei só pune o ato, é preciso levar em consideração, de outro, a função de exemplaridade da punição dos infratores para os demais. A tendência individualizante da lei e a inserção de saberes médicos, psicológicos e das ciências humanas na avaliação do criminoso e no traçado de seu perfil, assim, indicaria um deslocamento operacional do homo penalis para o homo criminalis. O sinal dessa modificação pode ser lido na própria formação do campo da criminologia no final do século XIX, que se ocupa, em sua gênese, do grau de periculosidade, da personalidade e da forma de ressocialização do criminoso ${ }^{1}$. Nesse momento, a criminologia adquire os contornos de uma "antropologia criminal", que acaba por contribuir para o enxerto de uma série de elementos que inflam, via mecanismos próprios da norma, a mecânica econômica da lei (FOUCAULT, 2009).

Essa antropologia do criminoso que emerge com recurso à biologia, à psicologia e à genética irá trazer em seu cerne os traços do racismo científico, responsável por justificar a ligação direta entre determinados fenótipos raciais e a propensão à criminalidade. Assim, tratou-se cientificamente de legitimar a exclusão de determinadas parcelas da população com apelo à ameaça que elas poderiam representar aos demais, demonstrada pela sua tendência inata para o crime. Esse biodeterminismo, de corte racial e social, contribuiria para estigmatizar, principalmente, os sujeitos negros, que eram vistos como delinquentes devido à herança atávica de seus ancestrais primitivos. E, por isso, em defesa da sociedade, deveriam ser detidos e aniquilados, pois o discurso do medo passa a validar a segregação social e a intervenção necessárias:

A partir do momento em que se naturaliza uma imagem depreciativa, subalterna e inumana do outro, estão autorizadas medidas as mais radicais para afastar do convívio social a ameaça representada por aquele ser. Fazer da diversidade sinal de ameaça e do medo o condutor das relações intersubjetivas é produzir um desenho institucional do extermínio da

\footnotetext{
${ }^{1}$ A tese de Cesare Lombroso, L'Uomo Delinquente, de 1876, é paradigmática em relação à investigação em torno do "criminoso nato", figura forjada pelo italiano para explicar o caráter hereditário do crime e que em muito contribuiu para o chamado racismo científico do século XIX. Cf. LOMBROSO, C. O Homem Delinquente. Trad. Sebastião José Roque. São Paulo: Ícone Editora, 2007.
} 
diferença. Assim atua o sistema penal desse tempo. Produz e reproduz uma horda de inumanos que, aos olhos da população e das instituições não passam de ameaças à realização de seus projetos individuais acerca da boa vida (PIRES, 2016, p. 200).

É na figura do homo oeconomicus que os neoliberais irão se concentrar, com vistas à compreensão do crime e da criminalidade pelo viés econômico, depurado de análises antropológicas. A definição de Gary Becker indica os termos nos quais o problema do crime será colocado: "[...] chamo de crime toda ação que faz um indivíduo correr o risco de ser condenado a uma pena" (BECKER apud FOUCAULT, 2008, p. 344). Essa definição é próxima daquela adotada por diversos códigos penais, inclusive o francês, para o qual Foucault lança um olhar analítico: “[...] o delito, diz o código penal francês, é o que é punido por penas correcionais. [...] Crime é o que é punido pela lei, e ponto final” (FOUCAULT, 2008, p. 344). Definição genérica, mas que se diferencia daquela de Becker em função da perspectiva que adota: a descrição do código diz respeito ao ato, enquanto o entendimento neoliberal define o crime do ponto de vista do "sujeito de uma ação, do sujeito de uma conduta ou de um comportamento", interpretando-o como "[...] aquela coisa que faz [com] que ele corra o risco de ser punido" (FOUCAULT, 2008, p. 344-345).

A grade analítica neoliberal desloca-se para o sujeito individual, ou seja, o sujeito de decisão que toma para si o ônus da ação e dos efeitos de seu comportamento em termos econômicos, esperando sempre algum lucro:

\begin{abstract}
O criminoso não é nada mais que absolutamente qualquer um. O criminoso é todo o mundo, quer dizer, ele é tratado como qualquer outra pessoa que investe numa ação, que espera lucrar com ela e aceita o risco de uma perda. O criminoso, desse ponto de vista, não é nada mais que isso e deve continuar sendo nada mais que isso. Nessa medida, vocês percebem que aquilo de que o sistema penal terá de se ocupar já não é essa realidade dupla do crime e do criminoso. É uma conduta, é uma série de condutas que produzem ações, ações essas cujos atores esperam um lucro, que são afetadas por um risco especial, que não é simplesmente o da perda econômica, mas o risco penal, ou ainda, o risco da perda econômica que é infligida por um sistema penal (FOUCAULT, 2008, p. 346).
\end{abstract}

Jogo de riscos e perigos que fará com que o sistema penal tenha que reagir a uma oferta de crime. De maneira distinta, porém, daquela proposta por Beccaria e Bentham, pois, para esses reformadores, a punição encontrava sua justificativa no 
efeito daninho de um ato praticado, para o qual, em nome de um princípio de utilidade, se deveriam buscar medidas de reparação. Ao passo que, para os neoliberais, trata-se de, face a um mercado do crime, fornecer os instrumentos de ação e de discurso, os mecanismos e os procedimentos necessários para se gerar uma demanda negativa do crime, ou seja, que se coloque nos antípodas da oferta.

Não se objetiva, por essa via, a supressão exaustiva dos crimes, como sonhavam com seu cálculo penal os reformadores do século XVIII. Antes, visa-se a propor medidas capazes de intervir no mercado do crime - quer dizer, sobre o jogo de ganhos e perdas possíveis -, e que sirvam como limites à oferta, elas mesmas circunscritas por um cálculo racional que não deve ultrapassar o custo da criminalidade de que se deseja barrar.

Vemos esboçar-se uma concepção que gravita em torno da ideia de gestão e economia política dos ilegalismos. Conforme interpreta Foucault (2008, p. 350), "[...] a boa política penal não tem em vista, de forma alguma, uma extinção do crime, mas sim um equilíbrio". A busca por esse ponto de estabilidade faz com que certas curvas de oferta de crime sejam absolutamente toleradas — e até desejáveis — para a manutenção da estabilidade e da regulação das políticas penais. Sabemos, ademais, a importância disso para a legitimação do próprio funcionamento dos aparatos e das políticas de repressão, que, em nome da segurança dos "cidadãos de bem", perpetram as maiores barbaridades contra grupos que ocupam a base da pirâmide social.

Essa situação é patente ainda hoje quando se trata, por exemplo, da política de "guerra ao tráfico de drogas", porque ninguém duvida da ineficácia do combate ao narcotráfico pela via das operações espetaculares em guetos, favelas e comunidades periféricas. Essas incursões não pretendem extinguir o tráfico de entorpecentes pela repressão exercida sobre o varejo, evidentemente ineficaz, mas são vetores de uma direção punitiva e seletiva endereçada àqueles que compreendem uma maior incidência de marcadores corporais da diferença. Daí a política de encarceramento massivo de certos segmentos populacionais, a pena de 
morte institucionalizada e a seletividade punitiva orientada pelo racismo de Estado e pela "sujeição criminal” (MISSE, 2008).

Em linhas gerais, a interpretação dos teóricos neoliberais comporta uma série de deslocamentos que abalizam as análises a partir do comportamento econômico dos indivíduos e, particularmente, do indivíduo criminoso. O programa neoliberal inclui uma gama de diferenciações operatórias e uma rede de "intervenção do tipo ambiental", em prol dos processos econômicos e segundo o cálculo racional de custos e benefícios. Não é fortuito que as punições são moduladas e diferenciadas de acordo com limites de tolerância concedidos a alguns e negados a outros, pois a gestão dos ilegalismos, simultaneamente, promove a economia das diferenças e a penalização insidiosa das disparidades, visto que realiza a "contenção punitiva como técnica de governo" (WACQUANT, 2014, p. 121).

A partir desse cálculo, a vida passa a ser pautada extensiva e intensivamente pelos domínios securitários e previdenciários. Esses domínios, compreendidos em sentido alargado como conjunto de cálculos que movem as engrenagens da dinâmica de riscos e seguros, periculosidade e vigilância, custos e benefícios, serão os moldes de organização das sociedades securitárias-empresariais, para as quais vigiar e punir são contrapartidas indispensáveis do guardar, acumular e proteger.

Instrumentos provenientes da estatística são assimilados e tornam-se, por excelência, os indicadores de compreensão das variáveis sociais e econômicas, cujos referenciais são as grades analíticas e os gráficos matemáticos. Com base neles, toda uma rede de ajustes modulados, imprescindíveis para o governo das vidas e para economia das punições são planejados. Modelar a realidade, traçar limites e estabelecer balanços, com o objetivo de tornar mais efetiva sua assertividade, convertem-se em imperativos no tratamento de problemas que estão na lista de prioridades dos Estados.

Por esse motivo, os dispositivos de segurança mobilizados para o controle, o monitoramento e a gestão de campos estratégicos são, atualmente, alvos prioritários de atenção e investimento por parte de todos os governos. É preciso governar os corpos, mas, principalmente, as subjetividades e os interesses. Configura-se, assim, 
uma preocupação constante de investimento na securitização da vida cuja contrapartida é o "fazer morrer" daqueles cujas condutas são identificadas, no contrato racial e social do neoliberalismo, com a periculosidade orgânica.

Ora, é sintomático, todavia, que os campos da segurança pública e criminal sejam investigados de modo secundário nas análises políticas neoliberais, quando é patente o papel capital que desempenham hoje, - quer da perspectiva das elevadas quantias movimentadas nos orçamentos público-privados, quer nas intervenções militarizadas em prol da "segurança cidadã", ou na complexidade dos modos de subjetivação que ensejam. Os mecanismos modulados e diferenciais, as ameaças e a judicialização permanente da vida, nesse sentido, constituem uma "verdadeira inflação legal, inflação do código jurídico-legal para fazer esse sistema de segurança funcionar" (FOUCAULT, 2004, p. 9).

Porque, para a manutenção da ordem social e da seletividade do sistema penal, exigem-se sacrifícios. Daí, a outra face da segurança, nas formas da razão de Estado, ser o controle social violento, que tem como paradigma securitário o incremento da letalidade do sistema penal:

[...] Diante da absurda suposição - não desejada por ninguém - de criminalizar reiteradamente toda a população, torna-se óbvio que o sistema penal está estruturalmente montado para que a legalidade processual não opere e, sim, para que exerça seu poder com altíssimo grau de arbitrariedade seletiva dirigida, naturalmente aos setores vulneráveis. Esta seleção é produto de um exercício de poder que se encontra, igualmente em mãos dos órgãos executivos, de modo que também no sistema penal "formal" a incidência seletiva dos órgãos legislativo e judicial é mínima. (ZAFFARONI, 2001, p. 27)

Esse sistema estigmatizante encontra sua legitimidade no discurso de ressocialização do criminoso quando, na verdade, atua de forma embrutecedora e degradante em relação à figura social dos grupos encarcerados. O processo de marginalização social, pela via da intervenção penal, culmina por desumanizar os inimigos construídos e produzir a exposição à morte e o extermínio de corpos naturalmente descartáveis, residuais. Isso reproduz, finalmente, a violência contra a qual imagina reagir.

Interessante ressaltar não apenas o papel significativo desempenhado pelas instâncias jurídicas e penitenciárias no contexto penal, mas também aquele realizado pelas polícias, que definem cotidianamente quais condutas desviantes serão 
enquadradas como tais, de acordo com os estereótipos de raça, de classe e de posição social em questão, mediante a leitura dos signos corporais. Há, então, indivíduos mais ou menos vulneráveis ao sistema penal, de modo que, nas sociedades "livres" neoliberais, são reforçados os mecanismos de segregação social e racial. Por isso, a resposta criminalizante dos desvios “[...] requer, sem dúvida alguma, uma referência direta e personalizada ao autor, em sua condição pessoal e na situação particular em que teria levado efeito tal conduta" (ZAFFARONI, 2001, p. 258).

Não deixa de ser curioso, igualmente, o debate suscitado em torno da privatização das prisões quando o superencarceramento passa a ser uma realidade. Se a liberdade é um dos valores centrais do mercado neoliberal e a segurança o seu produto rentável, a pena privativa de liberdade, em contrapartida, se torna o mecanismo privilegiado da burocracia penal em resposta às desordens inerentes à disseminação da insegurança social e da consequente marginalização urbana.

Nas brechas da discussão acerca da legitimidade de punir, na fenda instaurada entre a função da prisão e o objetivo da empresa, multiplicam-se as situações violatórias e se reiteram as críticas ao cárcere como instrumento de controle social e de manutenção do status quo. Com o agravante de, associado à lógica das empresas, ser revestido da operação inerente ao capital privatista: gerar lucro por meio da expansão de sua clientela. Daí a prevalência da defesa do encarceramento em detrimento de alternativas penais, que agravam a superlotação das unidades prisionais, acentuam as práticas autoritárias no controle da violência e o racismo institucional que impõe penas mais duras e rigorosas aos segmentos historicamente subalternizados: negros e pobres. Como nota Lemgruber, a privatização das prisões:

É um negócio impulsionado pela caríssima política de "endurecimento" penal, cujo suposto objetivo é reduzir a criminalidade e aumentar a segurança da população, mas cujo real benefício acaba sendo uma maciça transferência de recursos públicos para os que exploram a chamada "indústria de controle do crime": como se ouve freqüentemente entre empresários do setor, "é só construir [as prisões] que eles [presos] virão" ("build and they will come"). O que significa também uma crescente subordinação do Sistema de Justiça Criminal aos interesses dessa "indústria": quanto mais repressivo o sistema, mais ela cresce; quanto mais alta a taxa de encarceramento, melhor (LEMGRUBER, 2011, p. 18). 
Endurecimento dos castigos, o terror do espetáculo penal, lucros garantidos. Afinal, a "defesa social" e a luta contra a criminalidade movimentam montantes expressivos dos orçamentos públicos e privados. Elas reafirmam a estratégia repressiva, distribuem e regulam a violência do Estado, ao qual caberá decidir pela “difusão de emergências vinculadas ao medo e ao caos" (BATISTA, 2003, p. 51). Extrair o lucro político e econômico do crime e da criminalidade é o imperativo do governo da emergência e da produção ativa de ambientes seguros pela regulação e gestão do extermínio calculado.

Pois, esse governo, enquanto desdobramento da governamentalidade biopolítica neoliberal, não substituiu, como uma linha contínua de sucessivas evoluções, o poder soberano e o disciplinar. Muito pelo contrário. É no bojo dessa racionalidade que se constata, junto às tecnologias de vigilância, a proliferação das ações do poder soberano dos Estados, quando estabelecem o corte e decidem quem pode viver e quem deve morrer. Em relação a isso, atenta Foucault:

\begin{abstract}
Vocês não têm mecanismos de segurança que tomam o lugar dos mecanismos disciplinares, os quais teriam tomado o lugar dos mecanismos jurídico-legais. Na verdade, vocês têm uma série de edifícios complexos nos quais o que vai mudar, claro, são as próprias técnicas que vão se aperfeiçoar ou, em todo caso, se complicar, mas o que vai mudar, principalmente, é a dominante ou, mais exatamente, o sistema de correlação entre os mecanismos jurídicolegais, os mecanismos disciplinares e os mecanismos de segurança (FOUCAULT, 2004, p. 10).
\end{abstract}

A segurança se torna, desse modo, uma das principais preocupações normativas da vida nos regimes democráticos da atualidade. A experiência habitual evidencia que essa preocupação tem um fundamento real, na medida em que se vê um alargamento crescente do uso das tecnologias de segurança, cada vez mais recorrentes, que perscrutam de cima a baixo a vida dos governados. Elas operam pela via das medições e aferições biométricas, da vigilância ininterrupta das câmeras de segurança, dos identificadores digitais e das nanotecnologias, dos monitoramentos algorítmicos, enfim, de uma gama de controles computo-informacionais e institucionais, que visam ao governo e à normalização das condutas.

Constata-se como a governamentalidade neoliberal intensificou o gerenciamento das populações se apoiando em práticas concorrenciais e de 
autoinvestimento produtivo. Se, por um lado, essa arte de governo produz as liberdades de que necessita, dispondo delas, por outro, consome e anula permanentemente essas mesmas liberdades. Não é de se estranhar, portanto, que essa dinâmica de produção-destruição contínua necessite recorrer a uma série de coerções, chantagens e ameaças que recolocam continuamente os indivíduos, em diversos graus, em contato com a insegurança. Sob o signo do perigo, a liberdade se erige como sustentáculo fundamental de um modelo societário que não cessa de recolocá-la em jogo permanente.

O que tem se trazido à tona, ademais, são as novas formas ainda mais complexas de controle, assujeitamento e disciplina que passam por instrumentos de vigilância individualizados, coleta de dados e classificação dos sujeitos que vão muito além do modelo do "panóptico" como paradigma para se pensar a vigilância hoje. Porque o que se discute atualmente nos termos da governamentalidade algorítmica indica que as práticas de perfilação e categorização com o apoio de "metadados", fornecidos pelas tecnologias digitais, protagonizadas tanto por grandes empresas quanto pelos Estados, operam pela "digitalização da vida própria”, segundo Rouvroy e Berns (2010).

Isso consiste em uma forma de controle que articula, simultaneamente, dispositivos de detecção, de classificação e de orientação de comportamentos passíveis de serem antecipados, devido à interpretação de dados gravados. O que se constitui como "[...] um poder que reside nos algoritmos de correlação estatística, articulado para um 'controle' ou mais ainda, uma antecipação de um novo tipo nas sociedades “digitais” (ROUVROY; BERNS, 2010, p. 88-89). E que redimensionaria as configurações de governo e modulação das condutas, cujos efeitos e tecnologias não deixam de afetar as instituições e as práticas sociais.

É a partir dessa dinâmica de promoção da liberdade e de penalização acentuada que se privilegiam os dispositivos de segurança como instrumentos técnicos essenciais da governamentalidade política, haja vista que:

A liberdade e a segurança, o jogo liberdade e segurança - é isso que está no âmago dessa nova razão governamental cujas características gerais eu lhes vinha apontando. Liberdade e 
segurança - é isso que vai animar internamente, de certo modo, os problemas do que chamarei de economia do poder própria do liberalismo (FOUCAULT, 2008, p. 89).

Vê-se formar, desse modo, um nexo inextrincável entre liberdade e segurança no interior dos neoliberalismos, que tornam o Estado, apesar dos pretensos esforços de minimização da interferência no âmbito econômico, altamente intervencionista do ponto de vista político-penal. $O$ tratamento da criminalidade, sob o prisma de uma análise disciplinar que precede ao crime, acarreta a consolidação de uma cultura punitiva, estruturalmente e institucionalmente racista.

A economia das penas e dos castigos que acompanha a governamentalidade neoliberal demonstra a expansão das funções instrumentais e simbólicas do aparelho penal (WACQUANT, 2014), que reorienta o Estado social em direção ao Estado penal. Essa refuncionalização é levada a cabo por meio da burocracia beligerante e da lógica punitiva que justifica a letalidade estatal e a dominação étnico-racial. Porque a penalização insidiosa que acossa os governados como contenção punitiva atinge, de modo diferenciado, os sujeitos econômicos. Há os capitais humanos de maior valor e outros menos valorados, pois os critérios étnico-raciais, de classe e de nacionalidade são fatores que mobilizam distintas estratégias das políticas de segurança pública. É para esse fato que atenta Hamann (2012, p. 112), quando lembra que "[...] a abordagem neoliberal para lidar com a pobreza, o desemprego e a falta de moradia crescentes não é simplesmente ignorá-los, mas impor julgamentos punitivos por meio de efeitos moralizantes de sua racionalidade política". Assim, a gestão social dos estados desloca-se para a gestão punitiva da miséria, dos corpos racializados e da marginalidade urbana, identificadas pelo leviatã neoliberal como mais propensos ao crime.

Despolitizam-se, de outro lado, os conflitos sociais e consagram-se os controles punitivistas, cujos efeitos moralizantes refletem-se no aumento avassalador das populações carcerárias ao redor do globo. Tratadas como criminosas, populações precarizadas e em situação de vulnerabilidade social são alvos fáceis de um poder que ainda exerce seu direito de morte e poder sobre a 
vida, em nome da segurança e da ordem coletivas contra alteridades portadoras do perigo imanente.

\title{
"No pain, no gain"
}

Acrescenta-se a essa criminalização, salienta Foucault (2008, p. 91), que "não há liberalismo sem cultura do perigo". Ser uma unidade-empreendedora de si exige viver inteiramente e intensamente no risco. E são os riscos de mercado que demandariam, por sua vez, recurso às tecnologias securitárias, na medida em que, "em seu discurso, o risco é dado como uma dimensão ontológica" (DARDOT; LAVAL, 2009, p. 428), isto é, correr riscos passa a ser inerente a uma vida de investimentos, empreendimentos e atividade:

\begin{abstract}
Isso, claro, acarreta certo número de consequências. Podemos dizer que, afinal de contas, o lema do liberalismo é "viver perigosamente". "Viver perigosamente" significa que os indivíduos são postos perpetuamente em situação de perigo, ou antes, são condicionados a experimentar sua situação, sua vida, seu presente, seu futuro como portadores de perigo. $\dot{E}$ essa espécie de estímulo do perigo que vai ser, a meu ver, uma das principais implicações do liberalismo (FOUCAULT, 2008, p. 90).
\end{abstract}

Interessante sublinhar, porém, que a gestão social e política dos riscos, na concepção neoliberal, é individualizada. É assim que os perigos são perpetuamente (re)produzidos, atualizados e colocados em circulação. Se o risco é englobado pelas esferas de mercado, tornando-se comercializável — e rentável —, não há grande novidade em constatar que a produção do sujeito do risco tem como contraface a geração do sujeito da segurança privada. Todos se tornam responsáveis individuais pelo seu futuro, às expensas do comum e da dimensão coletiva da existência, e transformam-se em unidades “autorreferenciadas", ou no que Ulrich Beck (2011, p. 133 et seq.) chama, em A Sociedade do Risco, de "agentes de sua própria subsistência, mediada pelo mercado".

A ideia de uma privatização dos mecanismos de seguro, em todo caso a ideia de que cabe ao indivíduo, pelo conjunto das reservas de que ele vai poder dispor, seja a título simplesmente individual, seja por intermédio das sociedades de ajuda mútua etc., [proteger-se dos riscos] esse objetivo é, apesar de tudo, o que vocês vêem em ação nas políticas neoliberais [...] É a essa tendência: a política social privatizada (FOUCAULT, 2008, p. 198-199). 
Com a governamentalidade e a entrada da questão do Estado no campo de análise do micropoder, concebendo esse último como "efeito móvel de um regime de governamentalidades múltiplas" (FOUCAULT, 2008, p. 106), o problema da segurança e da economia das punições, no interior de uma arte neoliberal de governo, chegará a certos impasses. A questão da vigilância disciplinar, é bem verdade, não desaparece desse horizonte, como mostrou-se anteriormente, pois a racionalidade política que se liga ao gerenciamento estatal dos problemas próprios às populações demanda a normalização disciplinar. Porque, se essa tecnologia de governo se preocupa, de um lado, com as variáveis globais que envolvem os planos sanitário, epidemiológico e econômico, permanecem indispensáveis, de outro, o investimento e a intervenção, em profundidade, no nível dos comportamentos.

Será preciso, então, não punir menos, porém punir melhor. Vê-se surgir uma concepção que funda o programa de gestão e da economia política dos ilegalismos. Conforme afirma Foucault (2008, p. 350), “[...] a boa política penal não tem em vista, de forma alguma, uma extinção do crime, mas sim um equilíbrio”. Nesse cenário, curvas de ofertas de crime serão toleráveis, pois é preciso governar a desordem e seus efeitos mais do que buscar "a solução final” para a questão do crime. Antes disso, é no bojo de um cálculo político-econômico e da gestão ótima das ilegalidades que repousa a questão da permissão-repressão dos delitos, da penalização e de seu reverso, a impunidade:

O ilegalismo não é um acidente, uma imperfeição mais ou menos inevitável. É um elemento absolutamente positivo do funcionamento social, cujo papel está previsto na estratégia geral da sociedade. Todo dispositivo legislativo organizou espaços protegidos e aproveitáveis, em que a lei pode ser violada, outros, em que ela pode ser ignorada, outros, enfim, em que as infrações são sancionadas. No limite, eu diria, simplesmente que a lei não é feita para impedir tal ou tal tipo de comportamento, mas para diferenciar as maneiras de burlar a própria lei (FOUCAULT, 2006, p. 50).

A arte governamental securitária consiste, sobretudo, em um controle de fluxos, baseado no discurso das razões de segurança, com vistas a governar os efeitos advindos das crises que irrompem, de tempos em tempos, no seio da racionalidade neoliberal. Crises, aliás, que, das catástrofes ambientais aos terrorismos 
transnacionais, reforçam o discurso da centralidade dos mecanismos de segurança em meio à suspensão da "ordem normal" do fluxo das coisas.

O paradigma biopolítico da segurança traz para o primeiro plano “[...] o problema da circulação e da regulação dos fluxos" (GROS, 2011, p. 121). Intervir no meio e controlar os processos de produção e de captação das forças exige a produção simultânea da liberdade e seu cancelamento, pois a segurança é a síntese de todos os medos. Maximizar a imprevisibilidade e redistribuir de modo desigual os riscos socialmente reconhecidos significa tanto diferenciar segundo a capacidade de prevenção de cada um, que escalona os grupos de acordo com uma escala de exposição diferenciada aos danos, como operar a regulação específica de raça e de classe que multiplica os riscos de morte a uns mais do que a outros.

É assim que a securitização da vida, em suas variadas estratégias de conjunto, da seguridade social à segurança pública, destina-se a gerir os riscos voltados aos "perigos" da vida cotidiana e que tendem a "[...] conceder a cada um uma espécie de espaço econômico dentro do qual podem assumir e enfrentar os riscos" (FOUCAULT, 2008, p. 198). É certo que isto desempenha um papel fundamental para a progressiva "governamentalização" do Estado, com seus programas de gerenciamento dos riscos sociais passíveis de atingir as diferentes camadas da população. Sob o paradigma da segurança, é necessário:

Proteger o interesse coletivo contra os interesses individuais. Inversamente, a mesma coisa: será necessário proteger os interesses individuais contra tudo o que puder se revelar, em relação a eles, como um abuso vindo do interesse coletivo. É necessário também que a liberdade dos processos econômicos não seja um perigo, um perigo para as empresas, um perigo para os trabalhadores. A liberdade dos trabalhadores não pode se tornar um perigo para a empresa e para a produção. Os acidentes individuais, tudo o que pode acontecer na vida de alguém, seja a doença, seja esta coisa que chega de todo mundo, que é a velhice, não podem constituir um perigo nem para os indivíduos nem para a sociedade (FOUCAULT, 2008, p. 89).

Nesse pacto de segurança, em que seguridade e risco são complementares, a produção de liberdade é análoga à multiplicação dos dispositivos de segurança, de vigilância e de controle. No horizonte da modernidade/colonialidade tardia, 
governar de modo eficiente a realidade centrada no mercado tornou-se um problema capital.

Ou, talvez, o problema do capital global conectado à emergência de uma arquitetura transnacional da segurança. Não é de admirar, assim, que a razão bélica e a razão criminológica estejam imbricadas e que se organizem em torno do significante da democracia, cuja definição se coloca perenemente em disputa, atravessada, no modo de governo neoliberal, pela linha de corte biopolítica e pela cisão entre os inimigos/delinquentes/suspeitos e os "cidadãos de bem".

E não é apenas isso. Os fluxos securitários de controle dos corpos se materializam nas redes capilares de individuação e de subjetivação pelo medo. Eles culminam na paranoia generalizada da constituição de faixas de fronteira, muros e zonas de segurança, no interior das quais os antagonismos rearticulam a selvageria "natural" dos mercados ao modo de ser fundamentado na regulação moral pela economia e modulada pela insegurança experimentada em graus diferenciados por cada indivíduo.

Assim, se de um lado a razão criminológica neoliberal é constituída por uma rede que articula elementos discursivos e institucionais, de outro, as dinâmicas distintas de enquadramento da criminalidade e de gestão dos ilegalismos são modificadas pelas diferentes configurações históricas, políticas e econômicas. A função regulatória do dispositivo carcerário, da seletividade penal e do racismo de Estado, porém, não pode ser menosprezada, na medida em que a economia das penas e dos castigos operada pelo governo neoliberal evidencia que "o dilema entre recuperar e punir dissolve-se, em verdade, na constatação de que o sistema constitui aparelho exemplarmente punitivo" (FISCHER; ADORNO, 1989, p. 78). Exemplarmente punitivo e fundamentalmente rentável: eis os imperativos da razão criminológica neoliberal que vigem em nosso tempo. 


\section{Referências}

AESCHIMANN, É. Pourquoi Michel Foucault est partout?. Le Nouvel Observateur, 21 dez. 2013. Bibliobs. Essais. Disponível em: < http://bibliobs.nouvelobs.com/essais/20131220.OBS0394/pourquoimichel-foucault-est-partout.html>. Acesso em: 21 abr. 2018.

BATISTA, V. M. O medo na cidade do Rio de Janeiro: Dois tempos de uma história. Rio de Janeiro: Revan, 2003.

BECK, U. Sociedade de Risco. Trad. Sebastião Nascimento. São Paulo: Editora 34, 2011.

DARDOT, P.; LAVAL, C. La Nouvelle Raison du Monde: Essai Sur la Société Néolibérale. Paris: Éditions La Découverte, 2009.

DELEUZE, G. Conversaçoes. Trad. Peter Pál Pelbart. São Paulo: Editora 34, 2013.

FISCHER, R. M.; ADORNO, S. Políticas penitenciárias, um fracasso? Lua Nova, v. 3, n. 4, p. 70-79, 1987.

FOUCAULT, M. Gerir os Ilegalismos [1975]. In: POL-DROIT, R. Michel Foucault. Entrevistas. Trad. Vera Portocarrero e Gilda Gomes Carneiro. São Paulo: Edições Graal, 2006.

FOUCAULT, M. Nascimento da Biopolítica. Trad. Eduardo Brandão. São Paulo: Martins Fontes, 2008.

FOUCAULT, M. Sécurité, Territoire, Population. Paris: Gallimard/Seuil, 2004.

FOUCAUlT, M. Sobre a prisão. In: FOUCAUlT, M. Microfísica do Poder. Org. e trad. Roberto Machado. Rio de Janeiro: Edições Graal, 1979.

FOUCAULT, M. Vigiar e Punir. Trad. Raquel Ramalhete. Petrópolis: Vozes, 2009.

GROS, F. Direito dos Governados, Biopolítica e Capitalismo. In: NEUTZLING, I.; RUIZ, C. M. M. B. (Org.). O (des)governo biopolítico da vida bumana. São Leopoldo: Casa Leiria, 2011.

HAMANN, T. H. Neoliberalismo, Governamentalidade e Ética. Revista Ecopolitica, São Paulo, n. 3, maio/ago. 2012. Disponível em: $<$ http://revistas.pucsp.br/index.php/ecopolitica/issue/view/755/showToc $>$. Acesso em: 20 jun. 2018.

LEMGRUBER, J. Controle da criminalidade: mitos e fatos. Think Tank, São Paulo, v. 15, p. 1-29, jun. 2011. Disponível em: <https://www.ucamcesec.combr/wp-content/uploads/2011/06/Controleda-criminalidade_mitos-e-fatos.pdf>. Acesso em: 24 dez. 2018.

MISSE, M. Sobre a acumulação social da violência no Rio de Janeiro. Civitas, Porto Alegre, v. 8, n. 3, p. 371-385, set./dez. 2008.

PIRES, T. Criminalização do racismo: Entre política de reconhecimento e meio de legitimação do controle social sobre os negros. Brasília: Brado Negro, 2016. 
ROSE, N.; MILLER, P. Political Power Beyond the State: Problematics of Government. The British Journal of Sociology, v. 43, n. 2, p. 271-303, 1992.

ROUVROY, A.; BERNS, T. Le nouveau Pouvoir Statistique: ou quand le controle s'exerce sur un réel normé, docile et sans événement car constitué de corps "numériques"... Multitudes, n. 40, p. 88-103, 2010.

WACQUANT, L. Foucault, Bourdieu et l'état pénal à l'ère néolibérale. In: ZAMORA, D. (Org.). Critiquer Foucault: Les Années 1980 et la Tentation Néolibérale. Bruxelles: Ed. Aden, 2014.

WACQUANT, L. Punir os pobres: A nova gestão da miséria nos Estados Unidos. Rio de Janeiro: Revan, 2003.

ZAFFARONI, E. R. Em busca das penas perdidas: a perda da legitimidade do sistema penal. Rio de Janeiro: Editora Revan, 2001.

RECEBIDO: 06/05/2019

APROVADO: $19 / 10 / 2019$

RECEIVED: 05/06/2019

APPROVED: $10 / 19 / 2019$ 